\title{
Regenerative Braking System for Series Hybrid Electric City Bus
}

\author{
Junzhi Zhang*, Xin Lu*, Junliang Xue*, and Bos Li*
}

Regenerative Braking Systems (RBS) provide an efficient method to assist hybrid electric buses achieve better fuel economy while lowering exhaust emissions. This paper describes the design and testing of three regenerative braking systems, one of which is a series regenerative braking system and two of which are parallel regenerative braking systems. The existing friction based Adjustable Braking System (ABS) on the bus is integrated with each of the new braking systems in order to ensure bus safety and stability. The design of the RBS is facilitated by Simulink [1] which is used to build an interactive, multi-domain simulator that is allows parametric variation of vehicle speed, State of Charge (SOC) for the batteries, and the maximum current to be allowed to the batteries from the RBS. The required braking forces as a function of wheel speed are modeled using dSpace[2]. A Hardwire-in-the-Loop (HIL) experimental setup is used for component testing, followed by road testing using the Chinese Urban Bus Driving Cycle. Results indicate that all three braking systems provide some energy recovery, with the serial RBS providing the best combination of energy recovery with acceptable drivability, safety and stability. Overall results confirm that regenerative braking systems can recover significant braking energy while operating in a safe and predictable manner.

Keywords: Regenerative Braking, Hybrid Electric Vehicle, Control Strategy

\section{INTRODUCTION}

Deceleration of a vehicle with a traditional braking system requires that the kinetic and potential energy of the vehicle be converted into thermal energy or heat through the action of friction. Studies show that in urban driving about one third to one half of the energy required for operation of a vehicle is consumed in braking [3,4]. With regenerative braking on hybrid electric vehicles, this vehicle kinetic energy can be converted back into electrical energy that can be stored in batteries for reuse to propel the vehicle during the driving cycle[5]. Therefore, regenerative braking has the potential to conserve energy which will improve fuel economy while reducing emissions that contribute to air pollution.

Two versions of regenerative braking[6] are currently available. The first type is serial regenerative braking that is based on a combination of a friction-based adjustable braking system with a regenerative braking system that transfers energy to the electric motors and batteries under an integrated control strategy. The second type is a parallel braking system $[7,8]$ in which the

*State Key Lab. of Automotive Energy and Safety

Tsinghua University, Beijing, China 100084

Phone: 010-62771839 friction- based braking system and the regenerative braking system are operated in tandem, without integrated control which means that neither the friction braking force nor the regenerative braking force can be adjusted easily.

The parallel regenerative braking system has the advantage of not requiring a complex control system and the existing friction based braking system can be used without alteration. However, the energy recovered by the regenerative braking system will be small, and the drivability of the vehicle may be adversely affected. On the other hand, a series regenerative braking system is more complex to implement than the parallel regenerative braking system, but the energy recovered will be higher and the drivability of the vehicle can be preserved. Three RBS have been designed and tested. The design and testing of these systems, including comparison with the original ABS, will be described in the remaining sections of this paper.

\subsection{Research Objective}

The research objective for this project has been to design and test regenerative braking systems on the hybrid electric bus shown in Figure 1. Parameters for this bus are given in Table 1 .

Regenerative Braking System for Series Hybrid Electric City Bus 


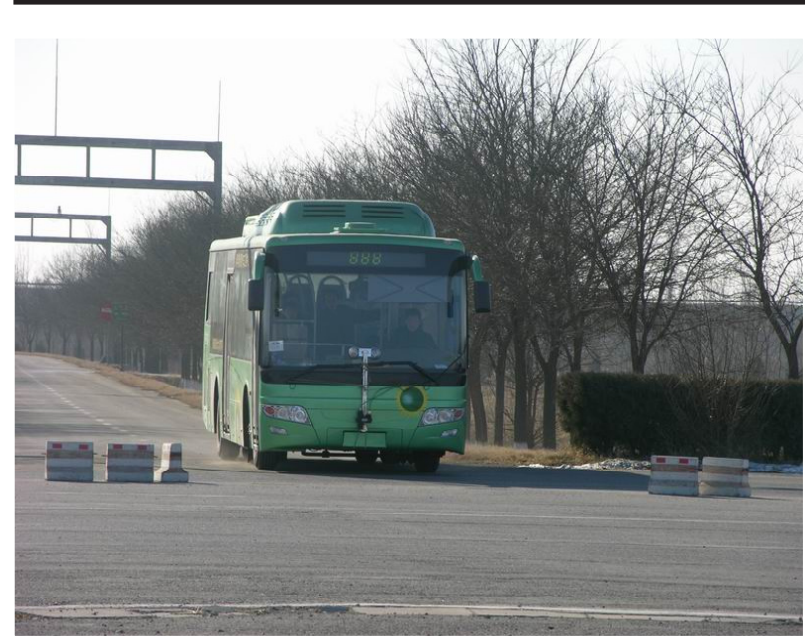

Figure 1: Hybrid electric bus

\section{DESIGNING THE SERIES RBS}

The drive train for the bus includes an Auxiliary Power Unit (APU) which consists of an internal combustion engine coupled to a generator and rectifier that can power the electric motor or charge the batteries as requested by the Vehicle Control Unit (VCU). The electric motor, which is controlled by the motor control unit, can work as a drive motor or a generator. The battery can drive the motor or absorb the current from APU and from the electric motor when the motor is working as a generator during regenerative braking.

The framework of the series RBS shown in Figure 2 consists of the RBS control unit, the ABS system, and two duty valves used to adjust friction braking force. The duty valves are installed in the front and rear brake lines.

The duty valves, which are also used in the ABS, are proven and have a quick response time. The different states of the two valves will determine the air pressure in the brake chambers. The brake control unit sends PWM signals to the valves to control the pressure, thereby controlling the mechanical braking force under the command of the control system of the RBS.

When the ECU detects a rear wheel lockup, the ABS controller emits a signal to activate the modulator valve which will cause the brakes to pulsate, thereby mitigating the wheel lockup condition. Since the RGS is installed on the rear axle, the same signal can be used to control the regenerative braking force and thereby improve vehicle stability by minimizing wheel lockup during hard braking operations.

\begin{tabular}{|c|c|}
\hline Name & parameter \\
\hline complete vehicle shipping mass $(\mathrm{kg})$ & 12200 \\
\hline maximum design total mass $(\mathrm{kg})$ & 15500 \\
\hline coefficient of aerodynamic resistance & 0.75 \\
\hline Wheel radius ( $\mathrm{m})$ & 0.512 \\
\hline final drive ratio & 6.833 \\
\hline Gearbox ratio & 2.46 \\
\hline overall efficiency of power train & 0.88 \\
\hline
\end{tabular}

Table 1: Vehicle parameters

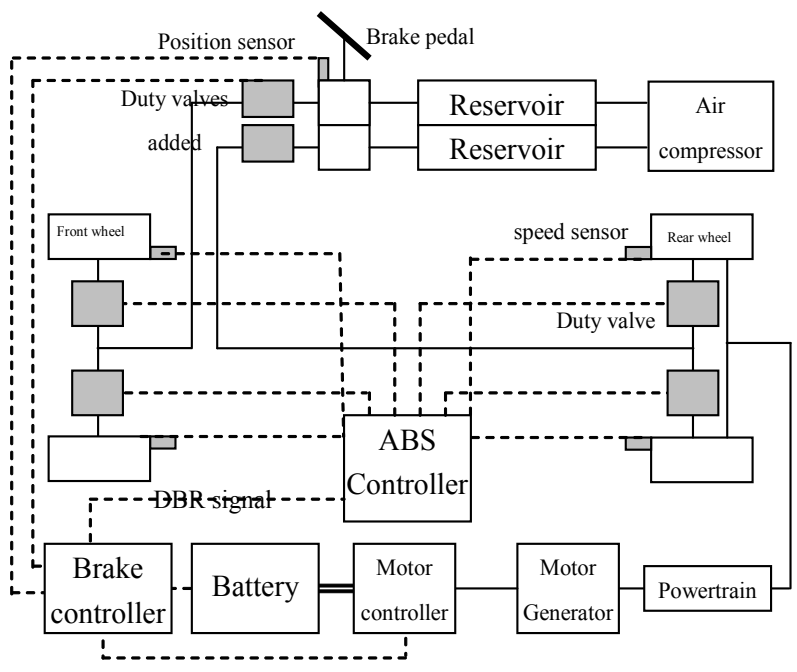

Figure 2: Serial RBS framework

\section{REGENERATIVE BRAKING STRATEGY TO ENSURE VEHICLE STABILITY}

Stability depends upon orderly application of braking forces. Of particular importance are the timing of the application of braking forces and the distribution of these forces between the front and back brakes. In this paper, three typical strategies for brake force distribution are studied. Primary attention is given to the Serial RBS, but with two strategies for Parallel RBS also studied for comparison purposes.

Figure 3 shows several strategies for optimizing braking force distribution between the front and rear wheels. The "ideal" front and rear braking force distribution is achieved when the braking forces acting on the front and rear axles are proportional to their corresponding loads during 


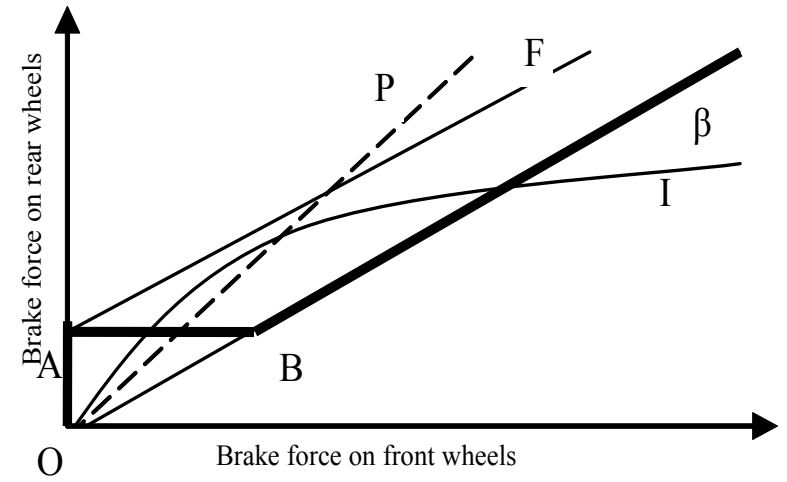

Figure 3: Braking force distribution

deceleration. If braking forces on front and rear axles follow the I curve shown in Figure 3, the front and rear axles will be locked simultaneously when the braking forces reach the adhesive limitation between the road and the tires [3].

In most vehicles the braking forces on front and rear axles are designed to follow the $B$ curve shown in Figure3.

The overall design strategy for the Serial RBS is for the brake controller to estimate the deceleration required by the driver and distribute the required braking force between the regenerative braking system and the mechanical braking system. Front and rear braking force distribution should ensure vehicle safety and stability.

In strategy of Serial RBS, the distribution of the braking force follows the thick solid line shown in Figure 3. From $\mathrm{O}$ to $\mathrm{A}$, all the braking force can be directed to the rear wheels which use the regenerative braking system to provide sufficient braking force. Using the rear braking under these light braking operations also insures vehicle stability. From A to B, the regenerative braking force is not sufficient for the total required braking force, so the mechanical braking force is needed on the front axle. From point B, the mechanical braking force on the front axle is at its maximum, so the increasing deceleration required by the driver must be supplied by increasing the mechanical braking forces on both axles simultaneously. After point $B$ the braking forces on front and rear axles follow the $B$ curve shown in Figure 3 , for the safety and stability of the vehicle.

When the ABS ECU detects that the rear wheels have locked up, the brake controller reduces the regenerative braking force and reverts to the mechanical braking only so that the ABS system can control the braking force effectively.

Two parallel RBS strategies are also shown in Figure 3. For Parallel RBS-1 the O-P curve in Figure 3 is used. The regenerative braking force is added to the mechanical brake force, which cannot be adjusted. The regenerative braking force is increasing with the mechanical brake force's increase.

For Parallel RBS-2 the braking force strategy is given by the curve $\mathrm{O}-\mathrm{A}-\mathrm{F}$ in Figure 3 . In this strategy, the beginning pedal travel is used to control the regenerative braking force, and the normal mechanical braking force is not changed.

\section{SIMULATION AND HIL}

\subsection{Simulation for RBS}

Before testing on the actual vehicle, the vehicle model is built and the strategy is tested through Simulink models of components. Figure 4 shows the framework which consists of a driver module, vehicle controller module, APU module, motor/ generator module, battery module, and vehicleroad module. Each module is independent and can be connected by simple signals, allowing the simulation of various drive train designs.

\subsection{Hardware-in-the-Loop Test-Bed}

In order to minimize the risk, a hardware-in-theloop test-bed was built for testing the strategy of serial RBS. The test-bed was made up of the air brake system, ABS and the serial RBS, which are the same on the actual vehicle.

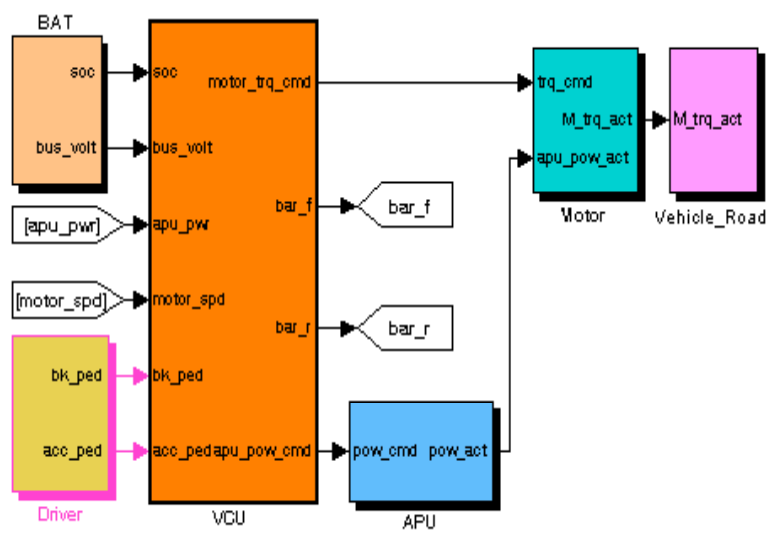

Figure 4: Vehicle model 


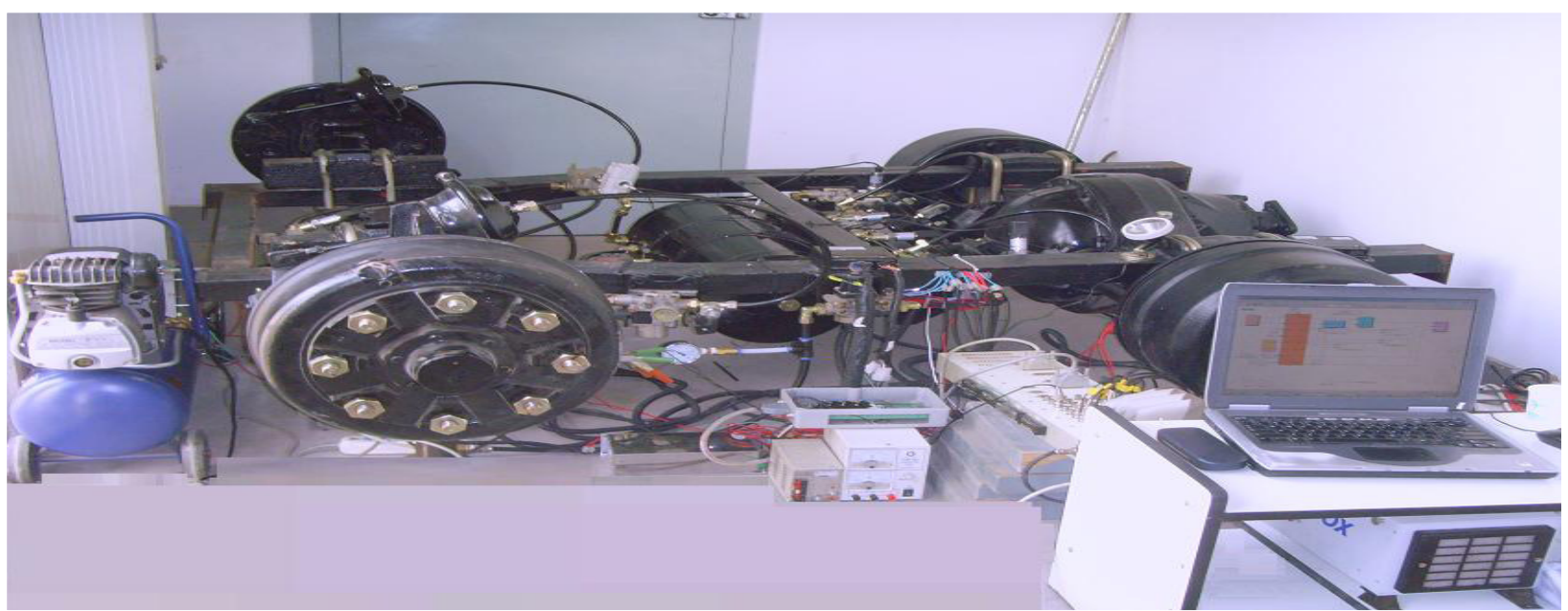

Figure 5: Hardware-in-the-loop test-bed

Several air pressure sensors are installed in the brake system for monitoring the pressure of brake line. Air pressure is measured behind the brake pedal, behind the additional duty valves and behind the original duty valves used by the ABS. The mechanical braking force is determined by air pressure in the brake chamber, so the mechanical braking force can be controlled by the duty valves that were added to the system.

The characteristics of the driver module, vehicle controller module, APU module, motor/generator module, battery module, and vehicle-road module are downloaded into dSPACE, which was connected to other parts of the test-bed. This is the hardware-in-the-loop test-bed, where the controls for adjusting the friction braking force can be tested and the braking strategies for controlling the regenerative braking and the ABS can be studied under controlled laboratory conditions.

The vehicle-road model running in the dSPACE can estimate wheel speeds by calculating the mechanical braking force, regenerative braking force, and the total braking force from the ground. The wheel speed signals are sent to the ABS controller, and the controller processes the signals. When the controller detects a wheel lockup, the unit activates the appropriate modulator valve, and air pressure is controlled. The signal is sent to the vehicle controller, and with other signals, for example, brake pedal position, the states of motor and battery, etc., the controller calculates the regenerative braking power and mechanical braking force required, and sends signals to control the duty valves via an I/O board. The whole hardware-in-the-loop test-bed is shown in Figure
5.

\subsection{Testing with HIL}

Figure 6 shows Chinese urban bus driving cycle. The vehicle speeds in this typical urban driving cycle show a high dynamic variation. The vehicle model is tested in this cycle to find the key factors affecting the performance of the regenerative braking. The speed and deceleration is constant in every cycle, while the SOC and the charge current limitation are varied to determine the effect on the regenerative braking.

The energy regeneration efficiency is defined as the ratio of the actual regenerated energy to the total kinetic energy that can be regenerated. Energy regeneration efficiency can be used to describe and compare the performance of the regenerative braking system and strategy.

Sample results are given in Table 2 for three cases. For Case A, the SOC is lower than Case B, thereby providing a greater opportunity for regenerative charging which for modeling purposes has not been restricted by setting the current limitation to infinity. It can be seen that Case A provides greater energy regeneration efficiency than case B. However, since some limitation on the current to the batteries will normally be required to protect the batteries from overcharging, Case C probably represents a more realistic situation. The added protection provided by limiting current reduces the theoretical energy regeneration efficiency to $52.6 \%$, but offers the benefit of assurance that the regenerative braking system will not overcharge the batteries. 


\begin{tabular}{c|c|c|c|c|c}
\hline NO. & $\mathrm{u}$ & SOC $/ \%$ & $\begin{array}{c}\text { Current } \\
\text { limitation } \mathrm{I} / \mathrm{A}\end{array}$ & $\begin{array}{c}\text { energy regeneration } \\
\mathrm{Q} / \mathrm{kJ}\end{array}$ & $\begin{array}{c}\text { energy regeneration } \\
\text { efficiency } / \%\end{array}$ \\
\hline A & 0.8 & 30 & infinity & 6354 & 65.4 \\
\hline $\mathrm{B}$ & 0.8 & 60 & infinity & 5948 & 61.3 \\
\hline C & 0.8 & 30 & 80 & 5100 & 52.6 \\
\hline
\end{tabular}

Table 2: Test on Chinese urban bus driving cycle

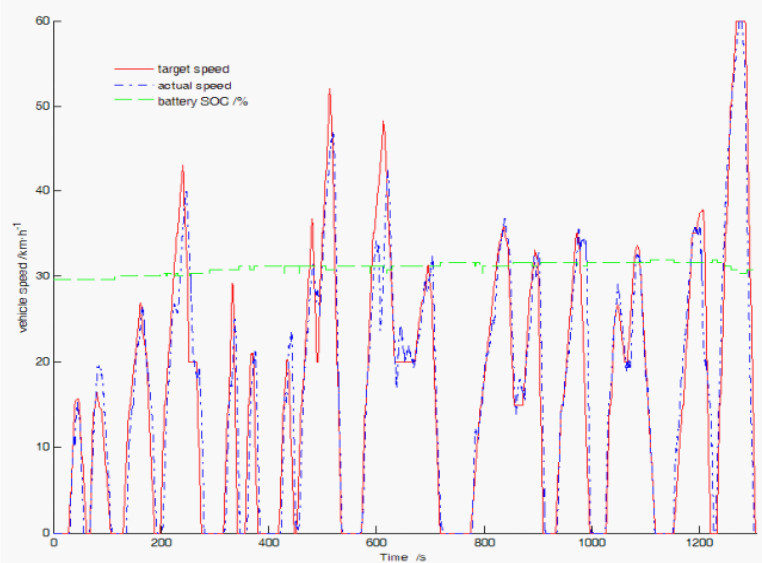

Figure 6: Chinese urban bus driving cycle

\subsection{Integrating the Serial RBS with the ABS}

The strategy for integrating the serial RBS with ABS is tested on the test-bed under several different conditions using the HIL. Representative results are shown in Figures 7 and 8. In the first scenario, the brake is applied at 1.8 seconds after which the motor brake torque is increased gradually. When the pedal position reaches $40 \%$, the wheels begin to lock up, one after the other. The ABS system then works to control air pressure, emitting a signal that decreases the regenerative braking gradually to zero, thereby assuring vehicle stability by transferring control of braking forces back to the ABS. The regenerative braking force is forbidden until the next brake application to avoid the switching back and forth that could cause the rear wheels to lock up frequently.

Figure 8 shows a scenario that results in locking up of the front wheels only. At 6.3 seconds after the brake is applied, the front wheels lock up when the pedal position is $38 \%$. Since the DBR signal is not changed, the regenerative braking force is still active on the rear axle. This strategy results in higher energy regeneration efficiency, but also produces the possibility that the front wheel lock up could cause the vehicle to become unstable.

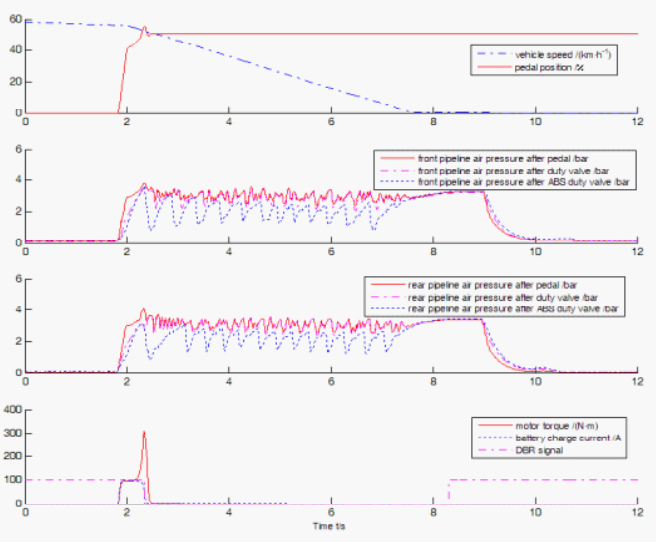

Figure 7: RBS working with ABS

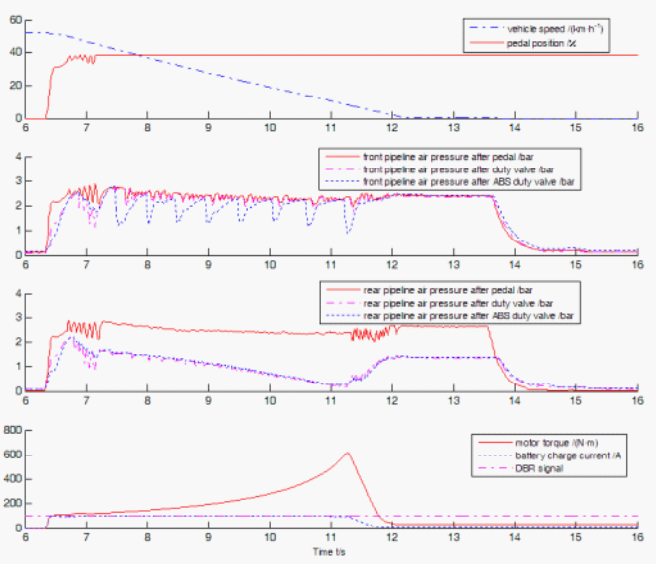

Figure 8: RBS working with ABS

\section{TESTING ON THE ROAD}

After completion of all laboratory testing, the new serial RBS was installed on the actual vehicle shown previously in Figure 1. A rapid prototype controller was built using dSPACE to control the actual vehicle via an I/O-board. The vehicle was tested on typical braking operations using the Chinese urban bus driving cycle with several 
strategies.

A typical result is shown in Figure 9. At 3.4 seconds, when the brake is applied, the motor speed is too great to provide sufficient regenerative braking torque (only $200 \mathrm{~N} \cdot \mathrm{m}$ ), so at 3.5 seconds the mechanical braking force is increased, and the voltage and current for regenerative braking is also increased. At 3.6 seconds, both reach their limit and the regenerative braking power is decreased by the vehicle controller. With the vehicle decelerating, the regenerative braking torque increases, so the rear air pressure is decreased to reduce the mechanical braking on the rear axle to satisfy the total required braking force. During this process, the brake pedal position has remained constant. From this test, it can be seen that the mechanical braking force can be adjusted quickly to support the serial RBS braking strategy, thereby providing significant energy regeneration efficiency without compromising vehicle stability or passenger safety.

Table 3 shows the resulting energy regeneration efficiency for the three RBS configurations along with the original (normal) hybrid electric bus configuration. The impact of the RBS on drivability is also noted, with acceptable results obtained for the serial RBS and Parallel RBS-1, but unsatisfactory drivability achieved with Parallel RBS-2.

With the same SOC, vehicle speed and deceleration, serial RBS strategy and Parallel RBS-2 have higher energy regeneration efficiency, but considering the drivability, serial RBS strategy is better than Parallel RBS-2. Parallel RBS-1 strategy has low energy regeneration efficiency and better drivability, because the regenerative braking force is light.

The three strategies proposed for RBS are also tested on Chinese urban bus driving cycle. Table 4 shows the results. The results are consistent with the performance predicted by the simulation model

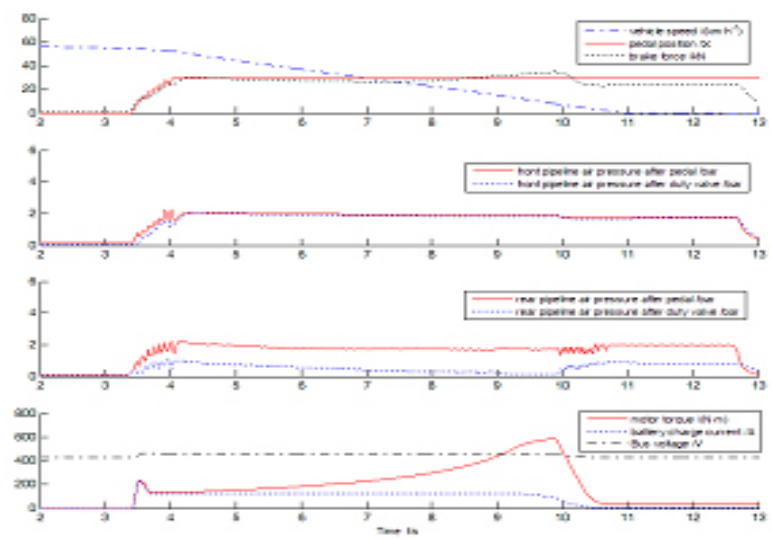

Figure 9: Test results for the serial RBS

and the experimental results obtained using the HIL test bed. Typically, the serial RBS strategy and the Parallel RBS-2 strategy always produced higher energy regeneration efficiency than the Parallel RBS-1 strategy.

\section{CONCLUSIONS}

In this paper, a methodology for designing a RBS has been described. Three RBS's were built and tested, first using a HIL test bed and then installed on an operation hybrid electric city bus. For the serial RBS, a key problem of how to adjust the friction braking force has been solved. Some factors have been taken into account for increasing the energy regeneration efficiency. How the RBS reacts with the ABS has been analyzed to ensure the vehicle's longitudinal stability. The results indicate that the serial RBS has a high energy regeneration efficiency while retaining acceptable vehicle drivability and stability needed to ensure passenger safety.

\section{REFERENCES}

[1] http://www.mathworks.com/products/simulink/

\begin{tabular}{|c|c|c|c|c|c|c|c|c|}
\hline $\begin{array}{c}\text { Test } \\
\text { Number }\end{array}$ & Strategy & $\begin{array}{c}\text { Vehicle } \\
\text { speed } \\
\mathrm{km} / \mathrm{h}\end{array}$ & $\begin{array}{c}\mathrm{SOC} \\
\%\end{array}$ & $\begin{array}{c}\text { Brake } \\
\text { intensity }\end{array}$ & $\begin{array}{c}\text { Total } \\
\text { energy kJ }\end{array}$ & $\begin{array}{c}\text { energy } \\
\text { regeneration }\end{array}$ & $\begin{array}{c}\text { energy regeneration } \\
\text { efficiency } \\
\%\end{array}$ & drivability \\
\hline$(1)$ & Serial RBS & 30 & 30 & 0.1 & 551.3 & 365.82 & 66.36 & $\mathrm{~B}$ \\
\hline$(2)$ & Parallel RBS-1 & 30 & 30 & 0.1 & 579.31 & 75.173 & 12.98 & $\mathrm{~B}$ \\
\hline$(3)$ & Parallel RBS-2 & 30 & 30 & 0.1 & 545.33 & 415.84 & 76.25 & $\mathrm{D}$ \\
\hline$(4)$ & normal & 30 & 30 & 0.1 & - & - & - & $\mathrm{A}$ \\
\hline
\end{tabular}

Table 3: Typical test with different strategies 


\begin{tabular}{|c|c|c|c|c|c|}
\hline $\begin{array}{c}\text { Test } \\
\text { Number }\end{array}$ & Strategy & $\begin{array}{c}\mathrm{SOC} \\
\%\end{array}$ & $\begin{array}{l}\text { Available } \\
\text { energy } / \mathrm{kJ}\end{array}$ & $\begin{array}{c}\text { energy } \\
\text { regeneration } / \mathrm{kJ}\end{array}$ & $\begin{array}{c}\text { energy regeneration } \\
\text { efficiency } \%\end{array}$ \\
\hline (1) & Serial RBS & 29.6 & 10715 & 5988.5 & 55.89 \\
\hline (2) & Parallel RBS-1 & 29.6 & 12538 & 2843.9 & 22.68 \\
\hline (3) & Parallel RBS-2 & 29.2 & 10846 & 6926.3 & 63.86 \\
\hline
\end{tabular}

Table 4: Test with different strategies on Chinese urban bus driving cycle

[2] http://www.dspace.org/

[3] Yinmin Gao, Liping Chen, Mehrdad Ehsani. Investigation of the Effectiveness of Regenerative Braking for EV and HEV. SAE International SP-1466. 1999-01-2910. 1999.

[4] Mehrdad Ehsani, Yimin Gao, Karen L Butler. Application of Electrically Peaking Hybrid (ELPH) Propulsion System To A Full Size Passenger Car With Simulated Design Verification. IEEE Transaction On Vehicular Technology. Vol.48, No.6, Nov. 1999.

[5] Yimin Gao and Mehrdad Ehsani. Electronic Braking System of EV And HEV-Integration of Regenerative Braking, Automatic Braking Force Control and ABS. SAE paper 2001-01-2478.

[6] John M.Miller. Propulsion systems for hybrid vehicles. IEE power and energy series 45, London 2004.

[7] Motomu Kakiai, Toshio Taichi. Brake System of "Eco-Vehicle". 14th International Electric Vehicle Symposium(EVS14).

[8] Michael Panagiotidis, George J Delagrammatikas, Dennis $\mathrm{N}$ Assanis. Development and Use of a Regenerative Braking Model for a Parallel Hybrid Electric Vehicle. SAE International, 2000-01-0995.

\section{AUTHORS}

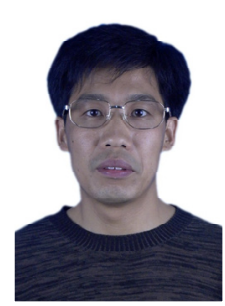

Junzhi Zhang, Associate Professor, State Key Laboratory of Automotive Safety and Energy , Tsinghua University, Beijing, China. Research interests include Automotive Hybrid Powertrain. He is currently researching the Optimization of Hybrid Powertrain, Energy Management of Hybrid Powertrain, and Control and Test of Hybrid Powertrain.

jzhzhang@mail.tsinghua.edu.cn

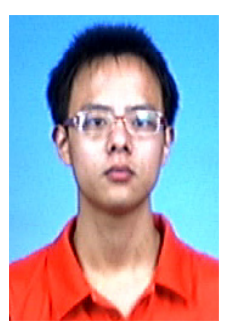

Xin Lu, Graduate, State Key Laboratory of Automotive Safety and Energy, Tsinghua University, Beijing, China. Research interests include Optimization of Hybrid Powertrain, Energy Management of Hybrid Powertrain, and Control and Test of Hybrid Powertrain. luxin06@mails.tsinghua.edu.cn 